\title{
Relasi Tanda pada Karakter Tokoh dalam Novel Rara Mendut Karya Y.B Mangunwijaya dan Kontribusinya Terhadap Pembelajaran Sastra di Sekolah Menengah Atas
}

\author{
Nurwahidah*, Kembong Daeng, Andiagussalin Aj \\ Program Pascasarjana Universitas Negeri Makassar \\ *Corresponding Author. Email: nurwahidahguntur94@gmail.com
}

\begin{abstract}
This study aims to describe the shape of the sign relations on character characters in the form of icons, indexes, and symbols as well as the contribution of novel Rara Mendut analysis to literature learning in high school. This research is a qualitative research using a literary semiotic approach with C.S. Peirce's sign theory. The data source in this study is the novel Rara Mendut by Y.B. Mangunwijaya. The data of this research is written data in the form of words, clauses and sentences contained in the text of the novel. Data collection techniques used is documentation, reading, and note-taking techniques. Data analysis techniques in this study is data reduction, data presentation, conclusions and data verification. The results of this study found that the figure of Rara Mendut as an icon of a brave and steadfast woman, the Pranacitra figure as a clever human icon, and the figure of Tumenggung Wiraguna as an icon of arbitrary ruler. The index found in this study includes the rejection of the of Rara Mendut character againts the proposal of the Tumenggung Wiraguna character and the true love story of the character Rara Mendut and Pranacitra. The symbols in this study is a symbols of Javanese culture that is thickly used by the characters in the novel. The results of this study can contribute as an alternative teaching material for learning literature in high school.
\end{abstract}

\begin{abstract}
Abstrak: Penelitian ini bertujuan untuk mendeskripsikan bentuk relasi tanda pada karakter tokoh berupa ikon, indeks, dan simbol serta kontribusi analisis novel Rara Mendut terhadap pembelajaran sastra di Sekolah Menengah Atas. Penelitian ini merupakan penelitian kualitatif dengan menggunakan pendekatan semiotika sastra dengan teori tanda C.S Peirce. Sumber data dalam penelitian ini yaitu novel Rara Mendut karya Y.B. Mangunwijaya. Data penelitian ini adalah data tulis yang berupa kata, klausa maupun kalimat yang terdapat dalam teks novel tersebut. Teknik pengumpulan data yang digunakan yaitu dokumentasi, baca, dan catat. Teknik analisis data dalam penelitian ini yaitu reduksi data, penyajian data, kesimpulan dan verifikasi data. Hasil penelitian ini menemukan bahwa tokoh Rara Mendut sebagai ikon wanita pemberani dan teguh pendirian, tokoh Pranacitra sebagai ikon manusia yang cerdik, dan tokoh Tumenggung Wiraguna sebagai ikon penguasa semena-mena. Indeks yang ditemukan dalam penelitian ini meliputi, penolakan tokoh Rara Mendut terhadap pinangan tokoh Tumenggung Wiraguna dan kisah cinta sejati tokoh Rara Mendut dan Pranacitra. Bentuk simbol dalam penelitian ini berupa simbol kebudayaan Jawa yang kental digunakan para tokoh-tokoh dalam novel tersebut. Hasil penelitian ini dapat berkontribusi sebagai salah satu alternatif materi ajar pembelajaran sastra di SMA.
\end{abstract}

\section{Article History}

Received: 02-05-2021

Revised: 21-06-2021

Accepted: 27-07-2021

Published: 07-09-2021

\section{Key Words:}

Semiotic, Icon, Index, Symbol, Characters, Literary Learning.

\section{Sejarah Artikel}

Diterima: 02-05-2021

Direvisi: 21-06-2021

Disetujui: 27-07-2021

Diterbitkan: 07-09-2021

\section{Kata Kunci:}

Semiotika, Ikon, Indeks, Simbol, Karakter Tokoh, Pembelajaran Sastra.

How to Cite: Nurwahidah, N., Daeng, K., \& Aj, A. (2021). Relasi Tanda pada Karakter Tokoh dalam Novel Rara Mendut Karya Y.B Mangunwijaya dan Kontribusinya Terhadap Pembelajaran Sastra di Sekolah Menengah Atas. Jurnal Kependidikan: Jurnal Hasil Penelitian dan Kajian Kepustakaan di Bidang Pendidikan, Pengajaran dan Pembelajaran, 7(3), 740-746. doi:https://doi.org/10.33394/jk.v7i3.3826 


\section{Pendahuluan}

Karya sastra merupakan refleksi pemikiran, perasaan, dan keinginan pengarang yang dituangkan melalui bahasa. Bahasa yang digunakan bukan sembarang bahasa melainkan bahasa yang memiliki ciri khas yakni memuat tanda-tanda atau semiotik (Endraswara, 2008). Tanda selalu hadir dalam kehidupan bermasyarakat dan digunakan dalam berinteraksi maupun berkomunikasi. Tanda selain sering dimanfaatkan sebagai wadah untuk berkomunikasi atau berinteraksi juga dapat dijadikan sebagai acuan, hubungan sebab akibat maupun berdasarkan kesepakatan masyarakat dalam memaknai setiap hal yang terdapat dalam kehidupan ini. Berdasarkan objeknya tanda terbagi atas tiga bagian, yakni ikon, indeks, dan simbol (Zoest, 1993). Ketiga bagian tanda tersebut sering digunakan pengarang dalam menyampaikan dan memahami pesan dan kritik sosial yang dimuat dalam karyanya, seperti novel. Baik itu melalui karakter para tokoh-tokohnya maupun peristiwa yang terjadi dalam alur ceritanya.

Novel yang dibuat seorang pengarang memiliki cerita kompleks dan panjang sehingga pengarang dapat menyampaikan gagasannya dengan baik dalam karya yang dihasilkannya. Novel adalah salah satu jenis karya sastra yang dibuat pengarang berdasarkan dengan pengalaman, pengamatan, dan latar belakang sosial kehidupannya. Setiap pengarang memiliki ciri khas tersendiri dalam penulisan setiap karyanya dalam mengungkapkan gagasannya. Pengarang juga biasanya memiliki gagasan tersembunyi dalam setiap karyanya sehingga untuk memahami hal itu diperlukan interpretasi mendalam untuk menemukan dan memahami makna tersebut. Selain itu, sebuah novel atau jenis karya fiksi yang menawarkan sebuah dunia yang berisi mengenai model kehidupan yang di idealkan. Novel juga digunakan sebagai media belajar bagi peserta didik di SMA (Fatimah dkk., 2021; Syarif dkk, 2021).

Novel dapat dikaji untuk mengungkapkan gagasan tersembunyi melalui relasi tandatanda yang digunakan pengarang baik itu melalui karakter atau watak tokoh-tokoh, alur atau peristiwa dalam penceritaannya. Salah satu pengarang yang menggunakan dan memanfaatkan tanda dalam karyanya, yakni Y.B. Mangunwijaya. Beliau biasanya menghasilkan karya-karya dengan gagasan yang kental dengan perjuangan kaum kelas bawah yang sarat dengan nilainilai kebudayaan tanpa meninggalkan sisi religius yang sering ditampilkan melalui setiap karakter tokoh yang diciptakannya. Adapun salah satu karya Y.B. Mangunwijaya yang dijadikan objek dalam penelitian ini yakni, novel Rara Mendut.

Novel ini menarik untuk diteliti karena pertama, tokoh utama dalam novel ini adalah perempuan. Kedua, tema sentral dalam novel tersebut tentang percintaan yang kental dengan kebudayaan Jawa tradisional. Ketiga, Y.B. Mangunwijaya sebagai pengarang dalam novel ini membahas mengenai budaya patriarki dan menonjolkan karakter tokoh-tokoh yang begitu kuat yang sehingga membuat ceritanya menjadi unik dan menarik. Untuk menemukan relasi tanda yang digunakan Y.B. Mangunwijaya pada novelnya tersebut melalui karakter setiap tokoh yang diciptakan untuk memahami maupun memaknai diperlukan teori yang tepat untuk menganalisisnya. Teori yang cocok digunakan dalam meneliti tentang tanda adalah teori semiotika, khususnya teori semiotika C.S. Peirce. Peirce membagi tanda berdasarkan objeknya menjadi tiga bagian, yakni ikon, indeks, dan simbol. Ikon merupakan hubungan tanda dengan petanda berdasarkan hubungan kemiripan. Indeks merupakan hubungan tanda dengan petanda berdasarkan hubungan kausalitas atau sebab akibat. Simbol merupakan hubungan tanda dengan petanda berdasarkan konvensi bahasa masyarakat (Zoest, 1993).

Pembelajaran sastra merupakan pembelajaran yang menyangkut seluruh aspek sastra yakni, teori sastra, sejarah sastra, kritik sastra, sastra perbandingan, dan apresiasi sastra. Dari semua aspek tersebut, apresiasi sastra merupakan aspek yang paling sulit. Sebab, apresiasi sastra menekankan pengajaran pada ranah afektif berupa rasa, nurani dan nilai-nilai 
(Ismawati, 2013). Guru memiliki peran penting dalam kegiatan belajar mengajar apresiasi sastra. Agar peserta didik sejak dini dapat tertarik pada novel atau jenis karya sastra lainnya yang sedang dibahas, guru hendaknya menunjukkan bagian yang menarik dari novel sebelum peserta didik membaca dan mengapresiasinya. Guru juga harus menggunakan metode yang bervariasi dan kreatif agar peserta didik memiliki minat belajar yang tinggi. Pembelajaran sastra terintegrasi dalam empat keterampilan berbahasa (mendengarkan, berbicara, membaca, dan menulis). Integrasi materi sastra dalam empat keterampilan berbahasa tersebut tujuannya adalah agar peserta didik memperoleh dan memiliki pengalaman berapresiasi sastra secara langsung. Hal ini diharapkan dapat menumbuhkan pengalaman penghayatan, penikmat, dan penghargaan siswa terhadap karya sastra (Emzir \& Wicaksono, 2018).

Penelitian terdahulu yang berkaitan dengan penelitian ini adalah penelitian yang dilakukan Muryati (2013) mengenai ideologi budaya Jawa yang dimiliki tokoh Genduk Duku dan Slamet yaitu seng ing pamrih rame ing gawe, narima ing pandum, temen, berbudi luhur, tirakat, pasrah dan rela. Penelitian lainnya dilakukan oleh Wibowo (2017) yang berfokus pada pemaknaan semiotik dalam novel Anomie karya Rilda A. Oe Taneko. Selanjutnya penelitian yang dilakukan oleh Septiana (2019) yang meneliti mengenai pandangan dunia pengarang dalam novel Rara Mendut karya Y.B. Mangunwijaya. ketiga penelitian ini memiliki persamaan dan perbedaan. Adapun persamaannya, masing-masing meneliti mengenai objek penelitian yang serupa yaitu, novel sedangkan perbedaan penelitian terdahulu dengan penelitian yang dilakukan oleh peneliti terletak pada masing-masing fokus penelitian dan pendekatan yang digunakan. Adapun kebaharuan yang ditawarkan dalam penelitian ini berupa gambaran analisis bentuk relasi tanda (ikon, indeks, dan simbol) pada karakter tokoh sebagai penggunaan tanda yang dibuat oleh pengarang dalam karyanya dan kontribusi analisis novel dalam pembelajaran sastra khususnya nilai pendidikan karakter di SMA. Adapun penelitian ini bertujuan untuk mendeskripsikan relasi tanda (ikon, indeks, dan simbol) pada karakter tokoh dalam novel Rara Mendut karya Y.B. Mangunwijaya melalui teori semiotika C.S. Peirce dan kontribusinya terhadap pembelajaran sastra di SMA.

\section{Metode Penelitian}

Metode penelitian yang digunakan dalam penelitian ini adalah penelitian kualitatif. Penelitian kualitatif merupakan proses pencarian data untuk memahami masalah sosial yang didasarkan pada penelitian menyeluruh, dibentuk oleh kata-kata dan diperoleh dari situasi yang alamiah (Moleong, 2011). Desain penelitian ini bersifat studi pustaka yang disajikan secara deskripsi kualitatif mengenai analisis novel Rara Mendut karya Y.B. Mangunwijaya tersebut.

Data yang digunakan dalam penelitian ini yakni data tulis berupa kata, klausa, atau kalimat penggalan dalam novel Rara Mendut karya Y.B. Mangunwijaya yang berbentuk narasi, dialog, dan monolog. Adapun sumber data yang digunakan dalam penelitian ini adalah novel karya Y.B. Mangunwijaya yakni novel Rara Mendut yang diterbitkan pada tahun 2019 oleh PT. Gramedia Pustaka Utama. Teknik pengumpulan data yang digunakan dalam penelitian ini adalah teknik dokumentasi, teknik baca, dan teknik catat. Teknik analisis data yang digunakan dalam penelitian ini mengikuti tiga tahap yakni reduksi data, penyajian data, kesimpulan dan verifikasi hasil penelitian dengan menggunakan teori semiotika C.S. Peirce (Miles \& Huberman, 2014).

\section{Hasil Penelitian dan Pembahasan}

Adapun hasil analisis dalam penelitian ini terbagi atas empat bagian. Pertama, bentuk ikon karakter tokoh pada novel Rara Mendut karya Y.B. Mangunwijaya yang menghasilkan 
tiga temuan. Kedua, ditemukan dua bentuk indeks karakter tokoh pada novel Rara Mendut karya Y.B. Mangunwijaya. Ketiga, simbol karakter tokoh dalam novel Rara Mendut karya Y.B. Mangunwijaya berupa simbol kebudayaan Jawa meliputi bahasa yang digunakan dan tata krama yang dilakukan oleh para tokoh didalamnya. Keempat, kontribusi hasil analisis novel Rara Mendut karya Y.B. Mangunwijaya terhadap pembelajaran sastra di SMA khususnya pendidikan nilai karakter.

\section{a) Bentuk Ikon Pada Karakter Tokoh}

Menurut Peirce, ikon merupakan tanda yang didasarkan atas "keserupaan" atau "kemiripan" (resemblance) diantara representamen dan objeknya, entah objek tersebut betulbetul eksis atau tidak. Hubungan itu adalah hubungan persamaan. Berdasarkan hasil pembacaan penulis terhadap novel Rara Mendut karya Y.B. Mangunwijaya tersebut ditemukan ikon meliputi:

Pertama, tokoh Rara Mendut sebagai penanda ikon wanita pemberani dan teguh pendiriaanya, pada novel tersebut dideskripsikan bahwa tokoh Rara Mendut ini adalah seorang gadis yang besar di perkampungan nelayan dan menjadi salah satu putri boyongan akibat peperangan yang terjadi antara Kadipaten Pati melawan kerajaan Mataram, namun tokoh Rara Mendut ini tidak serta merta menerima dirinya menjadi putri boyongan. Dia pun melakukan perlawanan dan berusaha untuk melarikan diri. Adapun salah satu kutipan mengenai bentuk sikap keberanian tokoh Rara Mendut sebagai penanda ikon adalah sebagai berikut:

"Sebab setiap kali tangan mereka menjamah tubuh Mendut, kaki sang gadis menggenjot perut; tangan menampar muka; dan tidak peduli kainnya sobek moratmarit lepas setengah telanjang, si harimau padang-padang pantai itu menampar, menyepak, menggarut begitu sengit, sehingga mereka terpaksa mengalah daripada kelas ditertawakan"

(Mangunwijaya , 2019: 37).

Kedua, tokoh Pranacitra sebagai penanda ikon manusia yang cerdik. Pada novel Rara Mendut diceritakan bahwa tokoh Pranacitra merupakan seorang anak saudagar kaya raya yang jatuh cinta kepada tokoh Rara Mendut. Segala cara dilakukan oleh tokoh Pranacitra untuk bisa menemui tokoh Rara Mendut yang tinggal di Puri Wiragunan. Salah satu kecerdikan yang dilakukan oleh tokoh Pranacitra melakukan penyamaran dengan berpura-pura untuk menjadi abdi atau pelayan bagi Tumenggung Wiraguna. Berikut salah satu kutipan datanya:

"Bersembahlah Pranacitra, Sudah hamba haturkan tadi, Kanjeng Raden Tumenggung. Keharuman bunga puri Panglima tenar selalu menghimbau kumbang-kumbang ladang. Cahaya dalam bandar ramai selalu menarik para pelaut yang merindukan kehangatan pelabuhan. Wiraguna dan Nyai Ajeng tersenyum, merasa tersanjung, padahal yang dimaksud Pranacitra adalah Mendut" (Mangunwijaya, 2019: 292).

Ketiga, tokoh Tumenggung Wiraguna sebagai penda ikon penguasa yang bertindak semenamena, dikisahkan dalam novel tersebut bahwa tokoh Tumenggung Wiraguna adalah seorang panglima dari kerajaan Mataram yang memiliki banyak istri tetapi di usianya yang sudah tidak muda lagi ia kembali jatuh hati kepada tokoh Rara Mendut dan berkeinginan untuk mempersuntingnya. Segala cara dilakukannya agar tokoh Rara Mendut mau menerimanya. Salah satu cara yang digunakannya dengan mengharuskan tokoh Rara Mendut untuk membayar pajak yang tinggi. Berikut salah satu kutipannya:

"Geram ia berkata kepada Nyai Ajeng, Baik. Mendut boleh membangkang. Tetapi dia dulu warga negara Pati, yang pernah memberontak melawan Mataram. Maka dia harus membayar pajak. Sampai ia bertekuk lutut" (Mangunwijaya, 2019: 154). 


\section{b) Bentuk Indeks Pada Karakter Tokoh}

Sebuah indeks dalam konsep Peirce merupakan sebuah tanda yang dalam hal corak tandanya tergantung dari adanya sebuah objek. Adapun bentuk indeks yang ditemukan dalam penelitian ini meliputi: penolakan tokoh Rara Mendut terhadap pinangan tokoh Tumenggung Wiraguna. Berikut salah salah satu kutipannya:

"Ternyata Tumenggung Wiraguna toh merana juga karena gagal meraih Mendut. Bahkan semakin ditolak, semakin penasaran keinginannya. Tetapi Wiraguna malu membuat heboh hanya karena soal perempuan. Kekerasan terhadap seorang wanita, semoga saja janganlah terjadi" (Mangunwijaya, 2019: 305).

Berdasarkan kutipan tersebut penolakan yang terus menerus dilakukan oleh tokoh Rara Mendut membuat tokoh Tumenggung Wiraguna semakin kecewa dan semakin penasaran untuk bisa menaklukan hati tokoh Rara Mendut. Meskipun pada akhirnya tokoh Tumenggung Wiraguna tetap tidak dapat memilikinya karena tokoh Rara Mendut memilih untuk melindungi kekasihnya, tokoh Pranacitra dari amukan tokoh Tumenggung Wiraguna yang murka karena mereka berdua berusaha untuk melarikan diri dari kerajaan Mataram dan telah membuat malu serta menginjak harga diri tokoh Tumenggung Wiraguna sebagai panglima kerajaan Mataram.

Bentuk indeks lain yang ditemukan adalah kisah cinta sejati antara tokoh Rara Mendut dengan tokoh Pranacitra. Kedua tokoh tersebut rela untuk mengorbankan nyawanya satu sama lain demi melindungi cinta sejati yang mereka yakini. Kedua tokoh ini telah berusaha untuk melarikan sejauh mungkin untuk bisa hidup bersama akan tetapi takdir berkata lain. Pelarian mereka berakhir ketika tokoh Tumenggung Wiraguna beserta pasukannya berhasil menemukan mereka sehingga terjadi pertarungan yang akhirnya merenggut nyawa keduanya.

\section{c) Bentuk Simbol Pada Karakter Tokoh}

Konsep Peirce mengenai simbol dapat diartikan sebagai tanda yang mengacu pada objek tertentu di luar tanda itu sendiri. Simbol merupakan sesuatu yang melaksanakan fungsi sebagai penanda yang oleh kaidah secara konvensi telah lazim digunakan dalam masyarakat. Bentuk simbol ditemukan pada novel Rara Mendut karya Y.B. Mangunwijaya meliputi simbol budaya Jawa yang dengan apik digunakan pengarang dalam novel ini. Baik itu dari segi penggunaan bahasa sehari-hari yang digunakan, tata krama dalam bersikap oleh para tokoh dalam novel ini beserta beberapa istilah yang sering digunakan di kehidupan masyarakat Jawa.

\section{Kontribusi Analisis Novel Terhadap Pembelajaran Sastra}

Berdasarkan temuan penelitian ini, analisis novel Rara Mendut karya Y.B. Mangunwijaya dapat berkontribusi menjadi salah satu bahan alternatif materi ajar dalam pembelajaran sastra khususnya pada pembelajaran mengenai nilai pendidikan karakter di SMA yaitu (1) secara historis novel Rara Mendut karya Y.B. Mangunwijaya ini mengisahkan lika-liku kehidupan Rara Mendut dengan yang berlatar waktu di zaman pemerintahan kerajaan Mataram Sultan Agung, melalui hal ini guru dapat memanfaatkannya sebagai materi bahan ajar dalam hal menilai karya sastra berdasarkan konteks historisnya, (2) novel Rara Mendut karya Y.B. Mangunwijaya memuat mengenai nilai-nilai pendidikan karakter yang disajikan oleh setiap tokoh, baik tokoh utama maupun tokoh pendukungnya seperti sikap bertanggung jawab, jujur, dan kesetiaan yang ditunjukkan oleh tokoh Rara Mendut dan Pranacitra yang berani mengambil resiko atas perbuatan mereka demi penyatuan cinta mereka. Terdapat juga sikap patuh dan menghormati yang ditujukkan oleh tokoh istri Tumenggung Wiraguna yang sangat menjung tinggi martabat suaminya dan selalu menjaga 
nama baiknya melalui setiap gerak gerik yang dilakukannya sesuai dengan tata krama kerajaan Mataram pada masa itu.

\section{Kesimpulan}

Berdasarkan hasil penelitian ini dapat disimpulkan bahwa bentuk relasi tanda yang ditemukan dalam novel Rara Mendut karya Y.B. Mangunwijaya adalah bentuk ikon karakter tokoh Rara Mendut sebagai wanita pemberani, tokoh Pranacitra sebagai manusia yang cerdik, dan tokoh Tumenggung Wiraguna sebagai penguasa yang semena-mena. Bentuk indeks pada karakter tokoh adalah penolakan tokoh Rara Mendut terhadap pinangan tokoh Tumenggung Wiraguna, dan kisah cinta sejati Tokoh Rara Mendut terhadap Tokoh Pranacitra. Bentuk simbol pada karakter tokoh yang ditemukan adalah simbol kebudayaan Jawa yang kental digunakan para tokoh-tokoh di dalam novel Rara Mendut karya Y.B. Mangunwijaya baik itu dalam bentuk percakapan antar tokoh, sikap para tokoh sesuai dengan tata krama kebudayaan Jawa maupun istilah-istilah yang sering digunakan oleh masyarakat Jawa. Hasil penelitian ini dapat dikontribusikan sebagai salah satu materi alternatif bahan ajar dalam pembelajaran sastra di SMA khususnya pendidikan karakter.

\section{Saran}

Berdasarkan hasil penelitian ini saran yang dapat disampaikann yakni sebagai berikut: (1) bagi guru bahasa Indonesia agar dapat dijadikan sebagai salah satu referensi dan materi alternatif bahan ajar dalam pembelajaran sastra di Sekolah Menengah Atas. (2) bagi peneliti selanjutnya, dapat dijadikan sebagai referensi peneliti lainnya yang ingin meneliti menggunakan pendekatan yang sama dengan objek penelitian (novel) yang berbeda maupun meneliti novel Rara Mendut karya Y.B. Mangunwijaya dengan menggunakan pendekatan dan teori sastra yang berbeda.

\section{Daftar Pustaka}

Al-Ma'ruf, A. I., \& Nugraha, F. (2017). Pengkajian Sastra Teori dan Aplikasi. CV. Djiwa Amarta Press.

Aminuddin. (2011). Pengantar Apresiasi Karya Sastra. Sinar Baru.

Emzir, R., \& Wicaksono, A. (2018). Tentang Sastra: Orkestrasi Teori dan Pembelajarannya. Garudhawaca.

Endraswara, S. (2008). Metodologi Penelitian Sastra: Epistemologi, Model, Teori dan Aplikasi. Pustaka Widyatama.

Fatimah, A. A. B., Syamsudduha, S., \& Usman, U. (2021). Analisis Wacana Kritis Novel Genduk Duku Karya Y.B Mangunwijaya dan Relevansinya dengan Pembelajaran Literasi Sastra berbasis Gender di SMA. Jurnal Kependidikan: Jurnal Hasil Penelitian dan Kajian Kepustakaan di Bidang Pendidikan, Pengajaran dan Pembelajaran, 7(2), 453. https://doi.org/10.33394/jk.v7i2.3741

Hamalik, O. (2013). Kurikulum dan Pembelajaran. Bumi Aksara.

Hoed, B. H. (2011). Semiotika dan Dinamika Sosial Budaya. Komunitas Bambu.

Ismawati, E. (2013). Pengajaran Sastra. Ombak.

Jabrohim. (2014). Teori Penelitian Sastra. Pustaka Pelajar.

Kaelan. (2009). Filsafat Bahasa Semiotika dan Hermeneutika. Paradigma.

Lickona, T. (2013). Educating for Character. Bumi Aksara.

Miles, M. B., \& Huberman, A. M. (2014). Analisis Data Kualitatif: Buku Sumber Tentang Metode-metode Baru (diterjemahkan Tjejep Rohendi Rohidi). UI Press.

Moleong, L. J. (2011). Metode Penelitian Kualitatif. PT Remaja Rosdakarya. 
Muryati, S. (2013). Ideologi Budaya Jawa dalam Novel Genduk Duku Karya YB Mangunwijaya. 22, 11.

Muslich, M. (2011). Pendidikan Karakter Menjawab Tantangan Kritis Multidimensional. Bumi Aksara.

Nitiasih, P. K., \& Hermawan, G. S. (2018). Semiologi: Simbol, Makna, dan Budaya. PT. Raja Grafindo Persada.

Nurgiyantoro, B. (2015). Teori pengkajian fiksi.Gadjah Mada University Press.

Nurgiyantoro, B., \& Efendi, A. (2013). Prioritas Penentuan Nilai Pendidikan Karakter dalam Pembelajaran Sastra Remaja. Jurnal Cakrawala Pendidikan, 3(3). https://doi.org/10.21831/cp.v3i3.1626

Nurrachman, D. (2017). Teks Sastra dalam Perspektif Semiotika Pragmatis Charles Sanders Peirce. Al-Tsaqafa: Jurnal Ilmiah Peradaban Islam, 14(1), 83-88. https://doi.org/10.15575/al-tsaqafa.v14i1.1793

Pradopo, R. D. (2014). Beberapa Teori Sastra, Metode, Kritik, dan Penerapannya. Pustaka Pelajar.

Salahuddin, A., \& Alkrienciehie, I. (2013). Pendidikan Karakter Pendidikan Berbasis Agama dan Budaya Bangsa. Pustaka Setia.

Septiana, H. (2019). Perempuan Jawa Dalam Novel Rara Mendut Karya Y.B. Mangunwijaya. $6(1), 15$.

Sobur, A. (2013). Semiotika komunikasi. Remaja Rosdakarya.

Sonesson, G. (2013). The Natural History of Branching: Approaches to the Phenomenology of Firstness, Secondness, and Thirdness. Signs and Society, 1(2), 297-325. https://doi.org/10.1086/673251

Stanton, R. (2007). Teori fiksi Robert Stanton. Pustaka Pelajar.

Sugiyono. (2010). Metode penelitian pendidikan: (Pendekatan kuantitatif, kualitatif dan $R \&$ D). Alfabeta.

Syarif, N., Tang, M., \& Usman, U. (2021). Idealisasi Nilai Pendidikan Lingkungan dalam Novel Anak Rantau (Kajian Ekokritik). Jurnal Kependidikan: Jurnal Hasil Penelitian dan Kajian Kepustakaan di Bidang Pendidikan, Pengajaran dan Pembelajaran, 7(2), 306-313. doi:https://doi.org/10.33394/jk.v7i2.3735

Tang, M. R. (2008). Mozaik Dasar Teori Sastra Dalam Penampang Objektif (1 ed.). Badan Penerbit UNM.

Teeuw, A. (2015). Sastra dan Ilmu Sastra. PT. Dunia Pustaka Jaya.

Wibowo, E. (2017). Makna Semiotik dalam Novel Anomie Karya Rilda A. OE. Taneko. 6(2), 13.

Yaumi, M. (2014). Pendidikan Karakter Landasan, Pilar, dan Implementasi. Prenadamedia Group.

Zoest, A. van. (1993). Semiotika Tentang Tanda, Cara Kerjanya dan Apa yang Kita Lakukan Dengannya. Yayasan Sumber Agung. 